\title{
Macrovascular complications in diabetics in the Centre for Diabetes Bjelovar during the period from January 2003 to April 2014
}

\author{
Saša Magaš*, Zrinka Sudar Magaš, Branko Flla \\ Bjelovar General Hospital, Bjelovar, Croatia
}

The goal: To present the incidence of macrovascular diabetic complications in outpatients in the Centre for Diabetes in the Bjelovar-Bilogora County during the period from January 2003 to April 2014.

Patients and Methods: Data were collected by using the database of the computer software CroDiab NET as a part of the national registry for diabetes. Risk factors prevalence and glycemic regulation data in diabetics of the Centre for Diabetes in Bjelovar Bilogora county have been already published. ${ }^{1}$ This study included 4,631 electronic health records processed during the follow-up period, considering the history of myocardial infarction, stroke, below ankle amputations, above ankle amputations and claudications.

Results: The most common macrovascular complication in this patient group is myocardial infarction (about $10 \%$ of patients). The second most common macrovascular complication was stroke ( $9 \%)$, followed by claudications $(4.58 \%)$, below ankle amputations (2.46\%) and above ankle amputa-

\section{Received: $17^{\text {th }}$ Apr 2014}

*Address for correspondence: Opća bolnica Bjelovar, Mihanovićeva 8, HR-43000 Bjelovar, Croatia.

Phone: +385-98-9027453

E-mail: sasa.magas@zg.t-com.hr tions $(2.06 \%)$. The lowest value of myocardial infarction was $7.4 \%$ in 2010 . The prevalence of patients with stroke also showed a downward trend from $14.9 \%$ in 2007 to $7.4 \%$ in 2012. Amputations below the ankle show the highest rate of $3.83 \%$ in 2007 , but with a clear downward trend to $1.56 \%$ in 2013 , and with further decline to $0.86 \%$ in the first four months of 2014. The frequency of amputations above the ankle shows even greater fall from $6.82 \%$ in 2003 to $0.88 \%$ in 2013 , followed by a further downward trend. Frequency of patients with claudications shows downward trend from $7.39 \%$ in 2003 to $3.45 \%$ in April 2014 .

Conclusions: The most common macrovascular complication was myocardial infarction, followed by stroke, and peripheral arterial insufficiency (claudications and amputations). The registered downward trend of macrovascular complications can be explained by good and even better glycemic control and management of cardiovascular risk factors. Good disease control pays off!

KEYWORDS: diabetic macrovascular complications, myocardial infarction, stroke, ankle amputations, claudications.

CITATION: Cardiol Croat. 2014;9(5-6):164.

\section{Literatura}

1. Magaš S. Incidence of modifiable cardiovascular risk factors and treatment of persons suffering from diabetes in the Bjelovar-Bilogora County during the period from 2001 to 2012. Cardiol Croat. 2013;8(7-8):246-253.

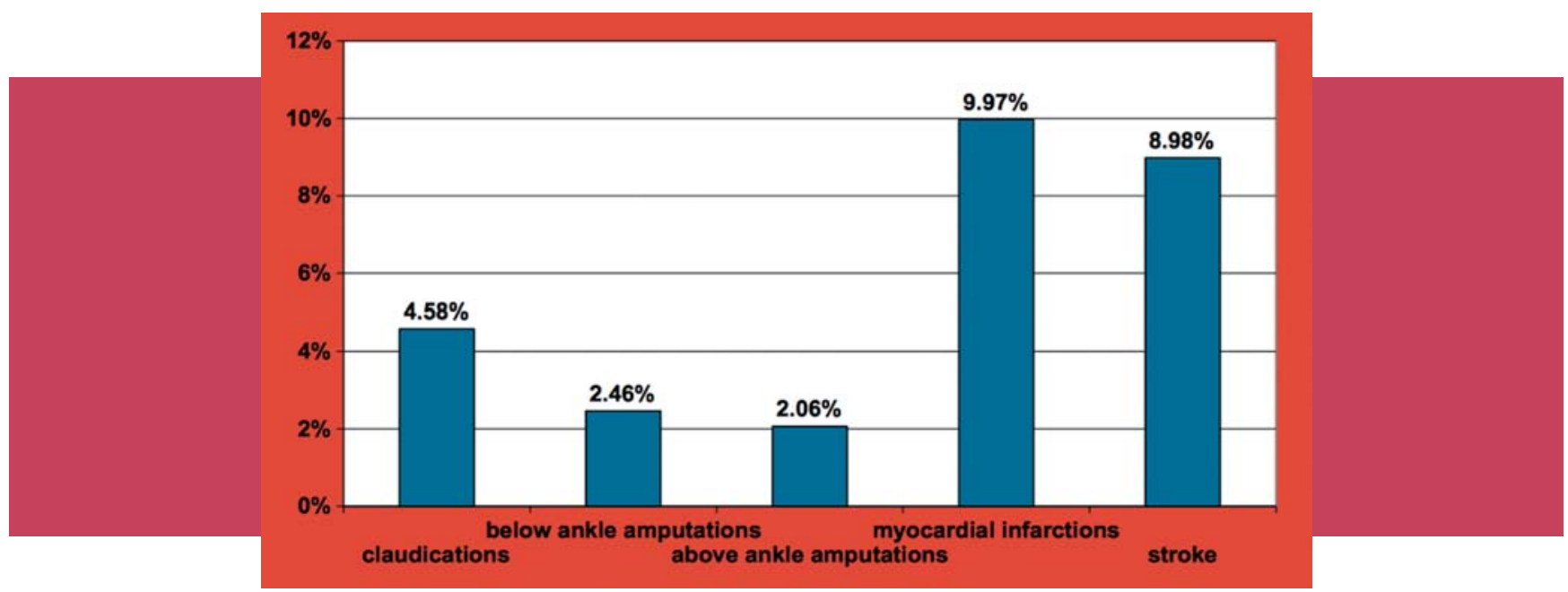

Figure 1. Macrovascular complications in Centre for Diabetes Bjelovar. 